\title{
Effect of Spinning Cycling Training on Body Composition in Women
}

\author{
Fatih Kaya ${ }^{1}$, Dilek Nar ${ }^{2}$, Mustafa Said Erzeybek ${ }^{3}$ \\ ${ }^{1}$ Department of Physical Education and Sports, Erzincan University, Erzincan, Turkey \\ ${ }^{2}$ The Vasil Levski National Sports Academy, Sofia, Bulgaria \\ ${ }^{3}$ School of Physical Education and Sports, Dumlupınar University, Kütahya, Turkey \\ Correspondence: Fatih Kaya, Department of Physical Education and Sports, Faculty of Education, Erzincan University, \\ Erzincan, 24100, Turkey.
}

Received: February 12, 2018

Accepted: March 12, $2018 \quad$ Online Published: March 18, 2018

doi:10.11114/jets.v6i4.3028

URL: https://doi.org/10.11114/jets.v6i4.3028

\begin{abstract}
In this study the effects of a 6 week spinning cycling training on the body composition of women were investigated. Twelve sedentary women (32-47 years old) voluntarily participated in this study. The 6-week training program consisted of exercise sessions on 3 days per week. The intensity of the training program that was kept low in the beginning was increased in the subsequent weeks. The training sessions including the warm-up and cool down lasted for 30-60 minutes. The analyses on the body compositions were measured regularly every week with bioelectrical impedance method. In data analysis descriptive statistics and repeated-measures analysis of variance were used. In the end of the 6-week spinning workouts positive changes were observed in many parameters related to body composition. Particularly after the 3rd week the significant changes recorded were noteworthy. At the end of the 6th week those who were overweight by World Health Organization (WHO) standards moved onto normal weight category and those who were obese became overweight. In conclusion it was seen that the spinning cycling workouts were seen as as effective method to lose weight and reduce the body fat ratio among women in this age group. This exercise method may be recommended for getting good results among obese and overweight women in a short period of time.
\end{abstract}

Keywords: indoor cycling, body composition, women

\section{Introduction}

Every day more and more people realize the benefits of aerobic exercise and incorporate them into their lifestyles. Activities such as step aerobics, zumba dance workouts or indoor cycling are very popular today (Thompson 2017). Particularly women prefer to participate in sports centers to benefit from such activities. Exercise proposals for women include rhythmic and dynamic long-term aerobic activities, including large muscle groups such as walking, running, swimming, cycling, shoveling, dancing, rope jumping (Galloway \& Galloway 2011).

Among these exercises are indoor cycling (spinning), an indoor fitness activity that combines aerobic and anaerobic exercises with participants' musical rhythms and pedal-on-the-go pedals on motivational words of an instructor (Caria et al. 2007, Hazelhurst \& Claassen 2006). During spinning, a very intense exercise program including a variety of cycling techniques such as climbing (cycling while standing), jumping (alternately sitting and standing for a period of time) and free-wheeling (cycling at a very fast pace) involving positions is applied (Hernandez 2001). Although it contains many high-intensity exercises, it can be impressive to engage in exercising when accompanied by music or animation (Kang et al. 2005).

In the studies carried out in this field, it is argued that spinning cycling workouts as a continuous medium-to-high-density exercise form lead to sufficient physiological responses (Kang et al. 2005), meet cardiorespiratory fitness and energy consumption demands, and they are suitable for those who want to increase and keep their cardiorespiratory capacities (Francis, Witucki \& Buono 1999, Bianco et al. 2010). It has been shown that environmental conditions where there is no wind flow, especially in a closed spinning studio, can lead to more sweating by raising the body temperature (Hazelhurst \& Claassen 2006, Brown \& Banister 1985) and may be a better fat burning exercise than an outdoor cycling (Galloway \& Galloway 2011). Even it can increase some cardiac biomarkers such as troponin and myoglobin levels (Duttaroy et al. 2012).

However, to date there is little information about physical and physiological responses to spinning cycling exercise. The main purpose of this study is to assess how well women participating in a typical spinning cycling class have earned achievement from this exercise. The secondary purpose is to investigate the effectiveness of spinning cycling workouts on body composition of this population. 


\section{Methods}

\subsection{Participants}

We included twelve sedentary women, aged between 32-47, attending a fitness center in Istanbul, Turkey in the study. The mean age of the participants was $38 \pm 5$ years, mean height $165 \pm 5 \mathrm{~cm}$, mean body weight $76.4 \pm 8.6 \mathrm{~kg}$, and mean body mass index $28.2 \pm 4 \mathrm{~kg} / \mathrm{m}^{2}$. All participants were novice at participating in spinning cycling classes. The random group design applied for the effect of exercise on body compositions. However, there was no control group. The participant's health status was determined by means of a Physical Activity Readiness Questionnaire (PAR-Q) (Thomas, Reading \& Shephard 1992). All participants were informed of the risks and benefits of the study and signed an informed consent. All procedures were conducted in accordance with the Declaration of Helsinki.

\subsection{Training Program}

This exercise program was a routine program used for beginners in fitness centers. However, the program was adapted according to the age and gender of the participants. An experienced instructor guided the spinning class through variable intensity work bouts, based on the participant's perceived exertion (3 days per week for 6 weeks) (Table 1). The intensity of the exercise training that was kept low in the beginning was increased in the following weeks (the principle of increasing load and adaptation). Training sessions were 30-60 minutes long, including the warm-up and cool-down periods. During the exercises, appropriate music was used in accordance with the varying intensity level. Spinning cycling workouts were performed at a cadence of 70-140 rpm and the positions of the body were frequently changed during the workouts (seated, standing, and climbing). Reebok Studio Exercise Cycles were used during spinning workouts.

\subsection{Data Collection}

Height and body mass measurements were made without shoes and light clothing with the Tem-Eko brand meter and body mass indexes were calculated $\left(\mathrm{BMI}=\mathrm{kg} / \mathrm{m}^{2}\right)$.

For body composition analysis, Bioelectrical Impedance Analysis (BIA) method was used (Tanita Body Fat Analyzer, model BC 418). The method is based on the difference between the lean tissue mass and the electrical permeability of the fat. The data of Lean Body Mass (LBM), Soft Lean Mass (SLM), Total Body Water (TBW), Body Fat (BF), Basal Metabolic Rate (BMR), Total Energy Expenditure (TEE), Impedance (IMP) and Percent of Body Fat (PBF) were calculated through body composition analysis (Ellis et al. 1999, McArdle, Katch \& Katch 1996). The measurements were made on a regular basis every week. During measurements, the weight of the clothes was not included in the measurements and the conductivity of the feet was increased by wiping with a damp cloth. BIA measurement requirements were provided for all participants.

\subsection{Statistical Analysis}

In the analysis of the data, we used descriptive statistics (mean and standard deviation) and repeated measures variance analysis performed with checks for sphericity. Post-hoc comparisons were performed with a Bonferroni adjustment of the alpha level (0.05). The level of significance was determined at $\mathrm{p}<0.05$, and analyses were done by the program SPSS 20.0 for Windows.

Table 1. 6-week spinning cycling training program

\begin{tabular}{|c|c|c|c|c|c|c|}
\hline & Week1 & Week2 & Week3 & Week4 & Week5 & Week6 \\
\hline Day1 & $\begin{array}{l}\text { 30min } \\
\text { 20min spin, only lower } \\
\text { gears, base level effort }\end{array}$ & $\begin{array}{l}35 \mathrm{~min} \\
25 \mathrm{~min} \text { spin, only } \\
\text { lower gears, base } \\
\text { level effort }\end{array}$ & $\begin{array}{l}40 \mathrm{~min} \\
30 \mathrm{~min} \text { ride all at } \\
\text { base }\end{array}$ & $\begin{array}{l}\text { 30min } \\
30 \mathrm{~min} \text { easy } \\
\text { spin all in } \\
\text { lower gears }\end{array}$ & $\begin{array}{l}40 \mathrm{~min} \\
30 \mathrm{~min} \text { ride all at } \\
\text { base }\end{array}$ & $\begin{array}{ll}40 \mathrm{~min} & \\
20 \mathrm{~min} \text { base, } & 5 \mathrm{~min} \\
\text { tempo, } & 5 \mathrm{~min} \\
\text { threshold } & \\
\end{array}$ \\
\hline Day2 & Rest & Rest & Rest & Rest & Rest & Rest \\
\hline Day3 & $\begin{array}{l}\text { 30min } \\
\text { 20min spin, only lower } \\
\text { gears, base level effort }\end{array}$ & $\begin{array}{l}35 \mathrm{~min} \\
25 \mathrm{~min} \text { spin, only } \\
\text { lower gears, base } \\
\text { level effort }\end{array}$ & $\begin{array}{l}40 \mathrm{~min} \\
30 \mathrm{~min} \text { ride all at } \\
\text { base }\end{array}$ & $\begin{array}{l}\text { 30min } \\
\text { 30min easy } \\
\text { spin all in } \\
\text { lower gears }\end{array}$ & $\begin{array}{l}50 \mathrm{~min} \\
\text { base } 40 \mathrm{~min} \text { ride }\end{array}$ & $\begin{array}{l}1 \mathrm{hr} \\
\text { base 50min ride }\end{array}$ \\
\hline Day4 & Rest & Rest & Rest & Rest & Rest & Rest \\
\hline Day5 & Rest & Rest & Rest & Rest & Rest & Rest \\
\hline Day6 & $\begin{array}{l}35 \mathrm{~min} \\
10 \mathrm{~min} \text { lower gears } \\
\text { base effort, } 15 \mathrm{~min} \text { at } \\
\text { tempo threshold }\end{array}$ & $\begin{array}{l}40 \mathrm{~min} \\
10 \mathrm{~min} \text { lower gears } \\
\text { base, then } 20 \mathrm{~min} \\
\text { tempo }\end{array}$ & $\begin{array}{l}50 \mathrm{~min} \\
40 \mathrm{~min} \text { long ride, } \\
\text { use all gears and } \\
\text { just ride }\end{array}$ & $\begin{array}{l}40 \mathrm{~min} \\
30 \mathrm{~min} \text { spin }\end{array}$ & $\begin{array}{l}\text { 1hr } \\
10 \mathrm{~min} \text { base, } \\
30 \mathrm{~min} \text { tempo, } \\
10 \mathrm{~min} \text { base }\end{array}$ & $\begin{array}{l}1 \mathrm{hr} \\
10 \mathrm{~min} \text { base, } \\
\text { 30min tempo, } \\
10 \mathrm{~min} \text { base }\end{array}$ \\
\hline Day7 & Rest & Rest & Rest & Rest & Rest & Rest \\
\hline
\end{tabular}

Note: 5 min warm up and 5 min cool down with low gears in each exercise session 


\section{Results}

The statistical analysis has revealed that all parameters, except BMR and TEE variables have been significantly changed (Table 2). Body weight (BW) has significantly and linearly decreased as from the start; $F(5,55)=103.253$, $\mathrm{p}<0.01)$. LBM has significantly decreased starting from week $3 ; \mathrm{F}(5,55)=24.353, \mathrm{p}<0.01)$. SLM has significantly decreased starting from week $3 ; \mathrm{F}(5,55)=13.440, \mathrm{p}<0.01)$. TBW has significantly decreased starting from week 4; $\mathrm{F}(5,55)=8.159, \mathrm{p}<0.01)$. Body fat has significantly decreased starting from week $2 ; \mathrm{F}(5,55)=62.892, \mathrm{p}<0.01)$. Although certain fluctuations has been observed for BMR during the process, these were not significant; $F(5,55)=1.489, p>0.05)$. Although certain fluctuations has been observed for TEE during the process, these were not significant; $F(5,55)=2.800$, $\mathrm{p}>0.05)$. IMP has significantly increased starting from week $4 ; \mathrm{F}(5,55)=5.523, \mathrm{p}<0.01)$. PBF has significantly decreased starting from week $3 ; \mathrm{F}(5,55)=22.988, \mathrm{p}<0.01)$. BMI has significantly decreased as from the start; $\mathrm{F}(5,55)=89.182$, $\mathrm{p}<0.01)$.

Table 2. Changes in body composition throughout the process, Mean (SD)

\begin{tabular}{lllllllll}
\hline & Week1 & Week2 & Week3 & Week4 & Week5 & Week6 & p-value & Sig. \\
\hline BW (kg) & $76.4(8.6)$ & $75.8(8.5)$ & $75.2(8.7)$ & $74.3(8.8)$ & $73.7(8.7)$ & $72.9(8.7)$ & 0.00 & $\mathrm{~s}$ \\
LBM (kg) & $50.1(3.4)$ & $49.8(3.4)$ & $50.0(2.6)$ & $48.9(3.4)$ & $48.4(3.4)$ & $47.5(3.6)$ & 0.00 & $\mathrm{~s}$ \\
SLM $(\mathrm{kg})$ & $45.8(2.9)$ & $45.6(3.1)$ & $45.4(2.9)$ & $44.7(3.0)$ & $44.1(3.2)$ & $42.5(4.8)$ & 0.00 & $\mathrm{~s}$ \\
TBW $(\mathrm{kg})$ & $35.7(2.3)$ & $35.9(2.6)$ & $35.7(2.5)$ & $35.3(2.7)$ & $34.8(2.7)$ & $34.2(2.8)$ & 0.00 & $\mathrm{~s}$ \\
Body Fat $(\mathrm{kg})$ & $26.9(6.1)$ & $26.2(5.9)$ & $25.3(6.1)$ & $24.9(6.3)$ & $24.3(6.2)$ & $23.5(6.0)$ & 0.00 & $\mathrm{~s}$ \\
BMR (kcal) & $1259.6(45.1)$ & $1260.3(42.7)$ & $1258.9(41.6)$ & $1265.5(53.1)$ & $1252.8(48.6)$ & $1248.6(48.4)$ & 0.25 & $\mathrm{~ns}$ \\
TEE (kcal) & $1420.5(87.7)$ & $1375.0(65.5)$ & $1389.3(43.1)$ & $1387.0(36.7)$ & $1380.3(44.4)$ & $1367.6(43.6)$ & 0.08 & $\mathrm{~ns}$ \\
IMP $(\Omega)$ & $428.2(47.6)$ & $429.8(51.5)$ & $422.9(42.4)$ & $434.7(48.7)$ & $438.0(48.4)$ & $441.2(50.5)$ & 0.00 & $\mathrm{~s}$ \\
PBF $(\%)$ & $35.6(5.1)$ & $34.9(5.4)$ & $34.6(5.3)$ & $33.5(4.6)$ & $32.7(4.7)$ & $32.0(4.7)$ & 0.00 & $\mathrm{~s}$ \\
BMI $\left(\mathrm{kg} / \mathrm{m}^{2}\right)$ & $28.2(3.7)$ & $28.0(3.6)$ & $27.7(3.7)$ & $27.4(3.7)$ & $27.2(3.6)$ & $26.9(3.6)$ & 0.00 & $\mathrm{~s}$ \\
\hline
\end{tabular}

$\mathrm{s}=$ significant at 0.05 level of confidence. $\mathrm{ns}=$ no significant at 0.05 level of confidence

Table 3 shows the changes in BMI at the end of a training period of six weeks for the participants. At the beginning, three participants were in the normal BMI category. The remaining nine participants were in the pre-obesity and obesity class-I BMI categories. At the end of the training period, the individuals in the normal BMI category have remained in their category, whereas six of the nine participants belonging to the pre-obesity and obesity class-I BMI categories have moved into the lower category.

Table 3. BMI changes in participants according to World Health Organization (WHO) classification

\begin{tabular}{|c|c|c|c|c|c|c|}
\hline ID & Week1 & Week2 & Week3 & Week4 & Week5 & Week6 \\
\hline 1 & Pre-obesity & Pre-obesity & Pre-obesity & Normal weight & Normal weight & Normal weight \\
\hline 2 & Pre-obesity & Pre-obesity & Pre-obesity & Pre-obesity & Pre-obesity & Normal weight \\
\hline 3 & Obesity class I & Obesity class I & Obesity class I & Obesity class I & Obesity class I & Obesity class I \\
\hline 4 & Obesity class I & Obesity class I & Obesity class I & Obesity class I & Obesity class I & Obesity class I \\
\hline 5 & Normal weight & Normal weight & Normal weight & Normal weight & Normal weight & Normal weight \\
\hline 6 & Pre-obesity & Pre-obesity & Pre-obesity & Pre-obesity & Normal weight & Normal weight \\
\hline 7 & Normal weight & Normal weight & Normal weight & Normal weight & Normal weight & Normal weight \\
\hline 8 & Obesity class I & Obesity class I & Obesity class I & Obesity class I & Obesity class I & Obesity class I \\
\hline 9 & Obesity class I & Obesity class I & Obesity class I & Pre-obesity & Pre-obesity & Pre-obesity \\
\hline 10 & Normal weight & Normal weight & Normal weight & Normal weight & Normal weight & Normal weight \\
\hline 11 & Pre-obesity & Pre-obesity & Pre-obesity & Pre-obesity & Pre-obesity & Normal weight \\
\hline 12 & Obesity class I & Obesity class I & Obesity class I & Obesity class I & Pre-obesity & Pre-obesity \\
\hline Ad & & WHO & for & over & 20 & jears \\
\hline
\end{tabular}

\section{Discussion and Conclusion}

The six weeks spinning cycling workout has resulted in various parameter changes regarding the body compositions. Particularly, the significant changes observed as from the third week were remarkable.

Studying the findings related with BW has demonstrated that body weights of the participants have been significantly decreased (approximately 4.7\%). This decrease has continued until the end of the training program. However, the total body weight is highly individual depending on the body type, ethnicity and training program. Thus considering the change in the body weight as the sole parameter for the evaluation of the progress can mislead and is not recommended. The decrease in the body weight is one of the primary expectations for the participants and is the first consideration for those participating to an exercise program, although it does not provide detailed and consistent data for the evaluation of the progress. Therefore, processing the body weight together with other body composition parameters would be much more beneficial. 
LBM comprises the weight of the bones, organs, tissues and muscles, exclusive of the body fat. Because the weight of your bones, organs and body tissues do not significantly change, LBM can be a direct measurement of muscle mass (Courseault 2018). Theoretically, as the LBM increases RMR also increases (Willis et al. 2012). A higher LBM enables lesser energy expenditure and the use of fat by increasing the metabolic rate. Our results show that LBM has significantly decreased starting from week 3 (total decrease 5\%). This finding suggests a decrease in the muscle tissue. Lean body mass was a function of body fat (Forbes 2000). Thus, the loss of fat free mass per unit of weight loss will be related to loss of body fat content. Additionally, lean body mass values reported for obese individuals of the same age and sex can be higher than those of normal weight individuals. This increased muscle mass is considered to be an adaptation to carry the extra body weight of obese subject. This extra protein is thought to be catabolized during weight reduction (Pavlou et al. 1985). Although spinning cycling workouts look like to the exercises with variable intense (e.g., interval training) physiologically, it has been reported that it is rather in the fartlek form (both aerobic and anaerobic capacities improve) (Francis, Witucki \& Buono 1999). Accordingly, the spinning exercises would provide rather metabolic and cardiovascular responses. Likewise, the resistance training increases muscle mass, and thus, increases LBM and total weight (Courseault 2018, Garrow \& Summerbell 1995, Willis et al. 2012). However, with regard to the weight loss workouts, it has been reported that a decrease in the non-fat tissue is also frequently observed together with the decrease in body weight (Stiegler \& Cunliffe 2006). Upon the meta analysis conducted, the researchers Garrow and Summerbell (1995) have reported that aerobic workout may cause loss in LBM (Garrow \& Summerbell 1995). Also, authors have indicated that weight loss only with aerobic exercises, without dieting is moderate and has very low effect on LBM. The meta analysis have revealed that for a weight loss of $10 \mathrm{~kg}$ by only dieting, the expected LBM loss is 2.9 $\mathrm{kg}$ for men and $2.2 \mathrm{~kg}$ for women. On the other hand, it has been observed that the loss in fat free mass by both dieting and exercising decreases to $1.7 \mathrm{~kg}$. Exercising together with diet enables to protect some of fat free mass by maintaining glycogen and water partly. It should be emphasized that the participants were not subjected to any diet and their diets were not monitored during our process.

In parallel with the decrease in LBM, also SLM has been significantly decreased starting from week 3 (total decrease 7.2\%). SLM is related with the skeleton muscle mass and internal organs. Accordingly, this decrease is not surprising.

As a part of SLM, also TBW has significantly decreased starting from week 4 . This result is consistent with the decreasing LBM and SLM. It has been reported that indoor conditions increase the perspiration rate by $36-38 \%$ (Hazelhurst \& Claassen 2006, Brown \& Banister 1985). Although no measurements have been performed at the end of each exercise session in this study, it has been shown that this decrease in the liquid loss continues during the whole process.

Based on the decreasing LBM and TBW, the impedance values of the participants has increased. This increase has become significant starting from week 3 . The change in the impedance values is an indicator of the change in the body tissues. The composition of the adipose tissue comprises $20 \%$ water on average. Accordingly, it does not transmit electrical current (the impedance of the adipose tissue is high). The impedance value of the muscle tissue is low since it comprises $75 \%$ water on average. Since most of the applied current passes through the muscle tissue, the impedance value of the muscle tissue is lower than fat (Buchholz, Bartok \& Schoeller 2004).

At the end of the process, Body Fat has significantly decreased starting from week 2 and PBF has significantly decreased starting from week 3. The total decrease in Body Fat is 12.5\%. For optimum health, the PBF range is 18-28\% for women (Lee \& Nieman 1995). Whereas in this study, the PBF value of the participants was $35.64 \%$ (SD 5.13) at the beginning and this was very high. However, at the end of the process, approximately $10.3 \%$ decrease has been observed. These results are highly important. Considering the change in the total body weight, it is possible to say that the weight loss is rather due to the fat. Several studies have demonstrated the effect of the regular aerobic workouts in terms of reducing the body fat. Thus, in the physical activity suggestions, it has been reported that either 30 minutes medium level exercise for 5 days a week or 20 minutes high level exercise for 3 days a week would be beneficial (Pescatello 2014, Haskell, Blair \& Hill 2009). Also, our previous study (Nar, Daglioglu \& Kaya 2013) has revealed similar results. The general body fat percentage is highly specific and varies from person to person. Therefore, it would be wrong to compare body fat percentages of the individuals. The decrease in Body Fat and PBF is an indicator of the achievements of the women who have participated to a spinning cycling training program of 6 weeks.

Although certain fluctuations have been observed for BMR and TEE during the process, no significant change has been determined. BMR is the most significant indicator of the metabolic rate. Whereas TEE is the sum of the calories required for the daily activities and BMR. Exercise training is associated with an increase in energy expenditure. However, while BMR constitutes 70 percentage of the daily energy expenditure, the physical activity's share is 20 percent, a limited part of it (Stiegler \& Cunliffe 2006, Preedy, Watson \& Martin 2011, Singh et al. 2010). The most widely used measure is resting metabolic rate (RMR). With regard to the long-term efficiency of the weight loss programs, the desired result is to maintain fat free mass and RMR while reducing the fat mass (Stiegler \& Cunliffe 2006). It has been reported that in general RMR is decreased during weight loss due to the decrease in non-fat tissue; 
and this decrease can be more important than those which are expected with the loss of non-fat tissue (adaptive thermogenesis) (Preedy, Watson \& Martin 2011).

It has been demonstrated that spinning workouts led to high calorie expenditure (Falsetti et al. 2010). It has been reported that compared to the constant load workouts, if the total intensity is kept same, it does not influence the metabolic and perceptual responses during exercising; however the spinning cycling workouts have the potential to increase the post-exercising energy expenditure (Kang et al. 2005). A study has revealed that after a spinning workout session of 45 minutes, the metabolic rate of the participants has increased for 14 hours on average and they have burned extra 190 calories over the resting metabolic rate (Knab et al. 2011). Also, it has been demonstrated that the calorie expenditure in a typical spinning cycling session is 300 to $600 \mathrm{kcal}$ (Francis, Witucki \& Buono 1999). This value conforms with the suggestion of the American College of Sports Medicine (ACSM) about the minimum calorie that should be spent during each exercise. This suggestion involves various physical activities resulting in 700 to $2000 \mathrm{kcal}$ expenditure for obtaining benefits (Pollock et al. 1998). Also, other suggestions for weight loss advise reducing the current energy intake by 500-1000 kcal and increasing gradually the physical activity of medium intensity that is performed at least 150 minutes per week to optimize health (ACSM 2013). Although no significant changes have been observed for BMR and TEE at the end of the process, this data indicate that the metabolic rate of our participants has increased after each cycling workout session and they have spent high amounts of calories. Consequently, the body fat and PBF values has decreased significantly.

BMI is a simple way to evaluate the obesity level independently from the body compositions. BMI is a good general indicator for population studies, however the general body composition is not considered. Thus, it imposes serious restraints when used for the analysis of the individuals.

It has been observed that at the end of the 6 weeks, 4 participants who were in the "pre-obesity" class at the beginning have passed into the "normal weight" class; and 2 participants who were in the "obesity class I" have passed into the "pre-obesity" class (half of the participants). This fact may be considered as one of the positive results of regular exercising. However, it should be kept in mind that unless the individual changes his/her diet, it is possible s/he loses much more less weight only by exercising. The research conducted to date show that when diet restraints are added to the exercise programs, this can cause more positive changes in the body composition compared to sole diet or physical activity (Stiegler \& Cunliffe 2006). As indicated before, the extra calories spent by exercising is only a small part of the total energy expenditure (less than 10 to 30 percent). In other words, if the individual does not restrict the calorie intake and maintain the daily intake same, the weight loss would be highly difficult. Particularly, over weighted or obese individuals should be careful about that. On the other hand, Slentz et al. (2004) has reported that even though the current diet is not changed, overweight and mild obese people would lose a small amount of weight by middle level exercising during 30 minutes each day. A constraint of this study is that the diets of the participants have not been monitored during the exercise period. Even though the participants have pursued exercising in this process, it is possible that they have in taken more calories. The studies show that people increases food consumption after exercising (either they think they have spent a lot of calories or they are hungry) (Preedy, Watson \& Martin 2011, Thomas et al. 2012).

As a result, this study shows that attending a spinning cycling class for optimum health, significant benefits may be obtained. Also, this study reveals that the spinning cycling exercises have positive effect on the body compositions of women in this age group.

We suggest more studies should be conducted about the effects of the diet restrictions and spinning exercising on the body composition and energy expenditure and evaluated in terms of acute and chronic aspects.

\section{Acknowledgements}

This study was presented as a paper at the 55th ICHPER•SD Anniversary World Congress \& Exposition, December 19-21, 2013.

The authors have no conflicts of interest that are directly relevant to the content of this study.

\section{References}

American College of Sports Medicine. (2013). ACSM's guidelines for exercise testing and prescription. Lippincott Williams \& Wilkins.p.322.

Bianco, A., Bellafiore, M., Battaglia, G., Paoli, A., Caramazza, G., Farina, F., \& Palma, A. (2010). The effects of indoor cycling training in sedentary overweight women. The Journal of Sports Medicine and Physical Fitness, 50(2), 159-165. PMID:20585293

Brown, S. L., \& Banister, E. W. (1985). Thermoregulation during prolonged actual and laboratory-simulated bicycling. European Journal of Applied Physiology

and Occupational Physiology, 54(1), 125-130. 
https://doi.org/10.1007/BF00426312

Buchholz, A. C., Bartok, C., \& Schoeller, D. A. (2004). The validity of bioelectrical impedance models in clinical populations. Nutrition in Clinical Practice, 19(5), 433-446. https://doi.org/10.1177/0115426504019005433

Caria, M. A., Tangianu, F., Concu, A., Crisafulli, A., \& Mameli, O. (2007). Quantification of Spinning® bike performance during a standard 50-minute class. Journal of Sports Sciences, 25(4), 421-429. https://doi.org/10.1080/02640410600718533

Courseault, J. (2018). Weight, Lean Body Mass and Exercise, Retrieved from http://www.drgourmet.com/exercise/weight.shtml, last modified: January 15, 2018

Duttaroy, S., Thorell, D., Karlsson, L., \& Börjesson, M. (2012). A single-bout of one-hour spinning exercise increases troponin T in healthy subjects. Scandinavian Cardiovascular Journal, 46(1), 2-6. https://doi.org/10.3109/14017431.2011.622783

Ellis, K. J., Bell, S. J., Chertow, G. M., Chumlea, W. C., Knox, T. A., Kotler, D. P., ... Schoeller, D. A. (1999). Bioelectrical impedance methods in clinical research: a follow-up to the NIH technology assessment conference. Nutrition, 15(11-12), 874-880. https://doi.org/10.1016/S0899-9007(99)00147-1

Falsetti, H., Blau, S., Burke, E., \& Smith, K. (2010). Heart rate response and calories burned in a spinning® workout. Spinning (R) Instructor Manual. Venice, Italy: Mad Dogg Athletics, Inc, B1.

Forbes, G. B. (2000). Body fat content influences the body composition response to nutrition and exercise. Annals of the New York Academy of Sciences, 904(1), 359-365. https://doi.org/10.1111/j.1749-6632.2000.tb06482.x

Francis, P. R., Witucki, A. S., \& Buono, M. J. (1999). Physiological response to a typical studio cycling session. ACSM's Health \& Fitness Journal, 3(1), 30-36. https://doi.org/10.1249/00135124-199901000-00010

Galloway, J., \& Galloway, B. (2011). Walking: A Complete Guide for Women. 2nd ed. United Kingdom: Meyer \& Meyer Verlag.

Garrow, J. S., \& Summerbell, C. D. (1995). Meta-analysis: effect of exercise, with or without dieting, on the body composition of overweight subjects. European Journal of Clinical Nutrition, 49(1), 1-10. PMID: 7713045

Haskell, W. L., Blair, S. N., \& Hill, J. O. (2009). Physical activity: health outcomes and importance for public health policy. Preventive Medicine, 49(4), 280-282. https://doi.org/10.1016/j.ypmed.2009.05.002

Hazelhurst, L. T., \& Claassen, N. (2006). Gender differences in the sweat response during spinning exercise. Journal of Strength and Conditioning Research, 20(3), 723. https://doi.org/10.1519/18155.1

Hernandez, F. J. (2001). U.S. Patent No. 6,287,239. Washington, DC: U.S. Patent and Trademark Office.

Kang, J. I. E., Chaloupka, E. C., Mastrangelo, M. A., Hoffman, J. R., Ratamess, N. A., \& O'connor, E. (2005). Metabolic and perceptual responses during spinning ${ }^{\circledR}$ cycle exercise. Medicine \& Science in Sports \& Exercise, 37(5), 853-859. https://doi.org/10.1249/01.MSS.0000161826.28186.76

Knab, A. M., Shanely, R. A., Corbin, K. D., Jin, F., Sha, W., \& Nieman, D. C. (2011). A 45-minute vigorous exercise bout increases metabolic rate for 14 hours. Medicine \& Science in Sports \& Exercise, 43(9), 1643-1648. https://doi.org/10.1249/MSS.0b013e3182118891

Lee, R. D., \& Nieman, D. C. (1995). Nutritional Assessment 2nd Ed. New York: McGraw Hill, p. 264

Mcardle, W. D., Katch, F., \& Katch, V. C. (1996). Exercise Physiology. Mcmillian Publishing Company First Edition, Baltimore; 151-163.

Nar, D., Daglioglu, O., \& Kaya, F. (2013). The investigation of the effects of 3-month fitness applications on body compositions in sedentaries. International Journal of Sport Studies, 3(8), 836-846.

Pavlou, K. N., Steffee, W. P., Lerman, R. H., \& Burrows, B. A. (1985). Effects of dieting and exercise on lean body mass, oxygen uptake, and strength. Medicine and Science in Sports and Exercise, 17(4), 466-471. PMID:4033403. https://doi.org/10.1249/00005768-198508000-00011

Pescatello, L. S., \& American College of Sports Medicine. (2014). ACSM's guidelines for exercise testing and prescription. Philadelphia: Wolters Kluwer/Lippincott Williams \& Wilkins Health.

Pollock, M. L., Gaesser, G. A., Butcher, J. D., Després, J. P., Dishman, R. K., Franklin, B. A., \& Garber, C. E. (1998). ACSM position stand: the recommended quantity and quality of exercise for developing and maintaining cardiorespiratory and muscular fitness, and flexibility in healthy adults. Medicine and Science in Sports and Exercise, 30(6), 975-991. https://doi.org/10.1097/00005768-199806000-00032 
Preedy, V. R., Watson, R. R., \& Martin, C. R. (Eds.). (2011). Handbook of behavior, food and nutrition. Springer Science \& Business Media. https://doi.org/10.1007/978-0-387-92271-3

Singh, M., Dureha, D. K., Yaduvanshi, S., \& Mishra, P. (2010). Effect of aerobic and anaerobic exercise on basal metabolic-rate. British Journal of Sports Medicine, 44(Suppl 1), i26-i26. https://doi.org/10.1136/bjsm.2010.078725.87

Slentz, C. A., Duscha, B. D., Johnson, J. L., Ketchum, K., Aiken, L. B., Samsa, G. P., ... \& Kraus, W. E. (2004). Effects of the amount of exercise on body weight, body composition, and measures of central obesity: STRRIDE-a randomized controlled study. Archives of Internal Medicine, 164(1), 31-39. https://doi.org/10.1001/archinte.164.1.31

Stiegler, P., \& Cunliffe, A. (2006). The role of diet and exercise for the maintenance of fat-free mass and resting metabolic rate during weight loss. Sports Medicine, 36(3), 239-262. https://doi.org/10.2165/00007256-200636030-00005

Thomas, D. M., Bouchard, C., Church, T., Slentz, C., Kraus, W. E., Redman, L. M., ... Heymsfield, S. B. (2012). Why do individuals not lose more weight from an exercise intervention at a defined dose? An energy balance analysis. Obesity Reviews, 13(10), 835-847. https://doi.org/10.1111/j.1467-789X.2012.01012.x

Thomas, S., Reading, J., \& Shephard, R. J. (1992). Revision of the physical activity readiness questionnaire (PAR-Q). Canadian Journal of Sport Sciences, 17(4), 338-345.

Thompson, W. R. (2017). Worldwide survey of fitness trends for 2018: The Crep Edition. ACSM's Health \& Fitness Journal, 21(6), 10-19. https://doi.org/10.1249/FIT.0000000000000341

Willis, L. H., Slentz, C. A., Bateman, L. A., Shields, A. T., Piner, L. W., Bales, C. W., ... Kraus, W. E. (2012). Effects of aerobic and/or resistance training on body mass and fat mass in overweight or obese adults. Journal of Applied Physiology, 113(12), 1831-1837. https://doi.org/10.1152/japplphysiol.01370.2011

World of Health Organization (2018). Ragional Office for Europe, Retrieved from http://www.euro.who.int/en/health-topics/disease-prevention/nutrition/a-healthy-lifestyle/body-mass-index-bmi

\section{Copyrights}

Copyright for this article is retained by the author(s), with first publication rights granted to the journal.

This is an open-access article distributed under the terms and conditions of the Creative Commons Attribution license which permits unrestricted use, distribution, and reproduction in any medium, provided the original work is properly cited. 